\title{
CORRIGENDUM
}

\section{Short-term supplementation with a specific combination of dietary polyphenols increases energy expenditure and alters substrate metabolism in overweight subjects}

J Most, GH Goossens, JWE Jocken and EE Blaak

International Journal of Obesity (2014) 38, 752; doi:10.1038/ijo.2014.21

Correction to: International Journal of Obesity (2014) 38, 698-706; doi:10.1038/ijo.2013.231; published online 9 December 2013

Since the online publication of this article the authors have noticed the following error.

In the final paragraph of the Discussion, the weight loss should be $1.4 \mathrm{~kg}$ rather than $3.4 \mathrm{~kg}$.
This error has now been rectified and the corrected article appears in this issue. The html and online pdf versions have also been amended.

The authors would like to apologize for this error. 